\title{
Writing and Translation with the James Bay Cree of Northern Québec
}

\author{
Ruth DyckFehderau
}
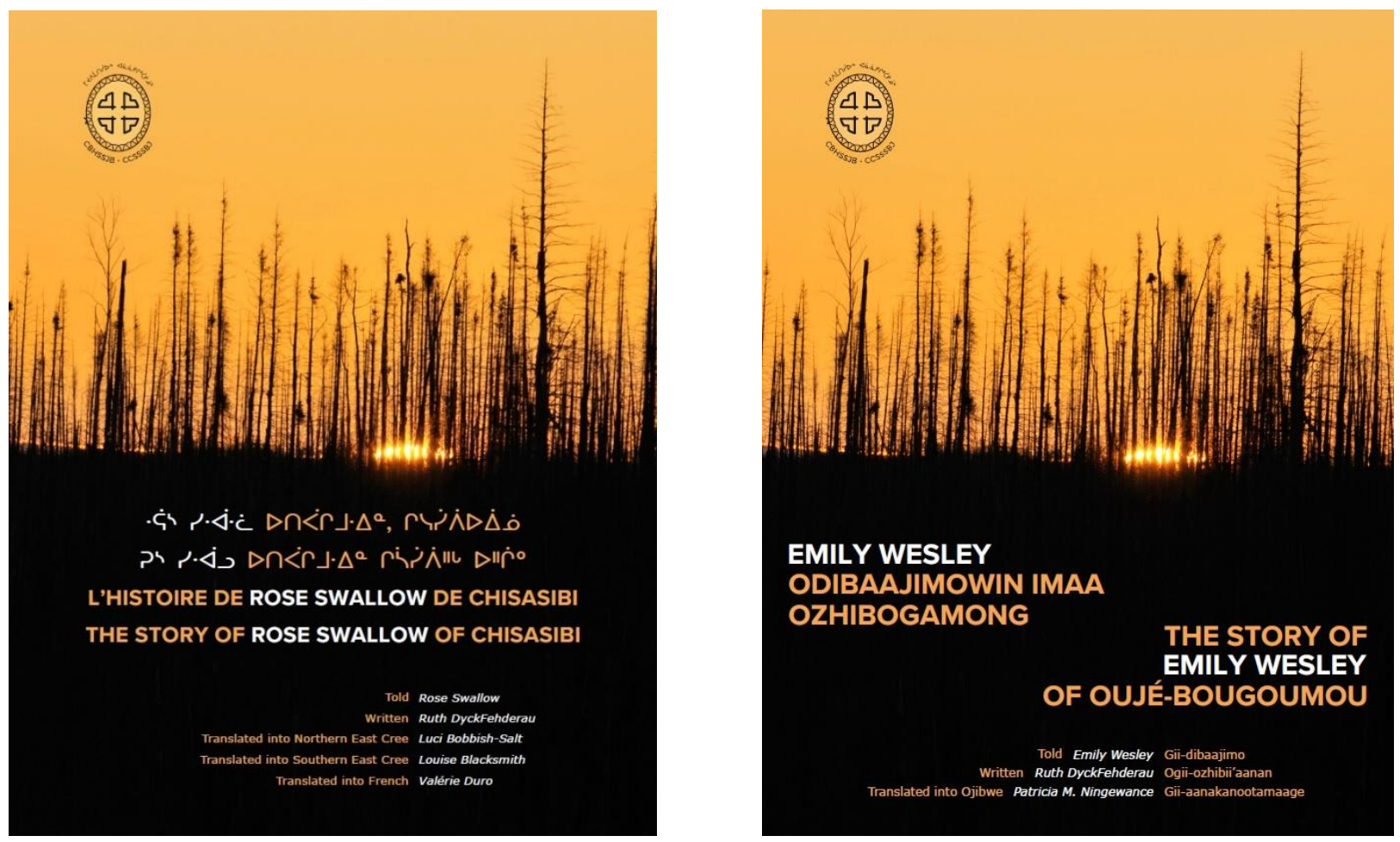

In about 2013, while I was living in the Cree territory of Eeyou Istchee in Northern Québec, I was commissioned by the public health sector of the James Bay Cree (Cree Board of Health and Social Services of James Bay, or CBHSSJB) to write stories of people in Eeyou Istchee who live with diabetes. Officially, it was to be a public health document, but in a literary format: story, in Cree culture, plays an important role in healing. CBHSSJB would hold copyright.

Over the next couple of years, my Cree supervisors sent me to each of nine Eeyou Istchee communities - the northernmost accessible only by plane or boat—and I listened as 28 individuals living with diabetes, some thriving, some barely coping, told me their stories. Sometimes, the storytelling would be over in an hour. Sometimes it went on for days. For the longer sessions, I joined storytellers at their homes as they talked and cooked or butchered moose or whatever they were doing that day. Or they dropped by my accommodations with another story to include or a detail to change and then stayed for tea. I had no set questions. They told me what they wanted me to know. 
After the story-gathering, I flew home to draft the stories. I had been given some (not many) parameters. For instance, the book had to contain many stories so no single story could be more than around 15 pages. Some of the stories, especially those of Elders, could have been much longer. And previously, in an effort to understand more about what they were looking for, I had written up one story in several different ways-word-for-word interview, magazine journalism, and so forth. My supervisors had preferred literary creative nonfiction in a short-story format with third-person narrators.

With drafts in hand, I returned to the communities where I sat down again with the storytellers. We combed the drafts together, line by line, word by word, and I edited accordingly. We did this as often as necessary until they approved of how their stories laid on the page. Then, since confidentiality was important to the project, I deleted all previous notes and recordings so that the finished stories approved by the tellers are all that now remains.

What this short process description doesn't say is that the project was very much a community undertaking. Beyond the storytellers themselves, many people had to participate for the project to come to fruition. They facilitated my travels across the vast and remote Eeyou Istchee (approximately $450,000 \mathrm{~km}^{2}$ ). They found me accommodations in communities where housing is at a premium. They contacted potential storytellers. They supported storytellers when the telling itself was emotionally difficult. They translated for me. They explained any number of cultural subtleties and histories that an outsider couldn't hope to understand. And they did so much more.

In fact, for several reasons, the gathering and crafting of the stories was itself an act of translation. First, and most obviously, I am not Cree. The James Bay Cree publish a great deal of material and have many accomplished writers, but for stories likely to include a fair amount of trauma, as some of these stories do, CBHSSJB sometimes hires outsiders. I've spent almost half my professional life living in cultures other than my own and know that every moment has nuances or personal responses I'd never be able to pick up.

Second, in Eeyou Istchee, almost everything happens in one of the Cree languages. Conversations around me were almost always in Cree-my Cree vocabulary includes about 25 words - and if it became necessary, someone would switch into English and translate for me. The storytelling itself, however, happened in English. We offered storytellers the option of speaking through translators, but all_-including those struggling in English—preferred to speak directly to me, alone. I believe this was partly because of the importance that many placed on confidentiality. (We hid identities if necessary.)

And third, I have lost a great deal of hearing and rely heavily on lip reading, something that can make people uncomfortable and can require yet another act of mediation. The storytellers seemed unfazed by my disability, and ready with What-did-the-deaf-man-say jokes. Indeed, they appeared to tell 
their stories openly and to take pleasure in the process. And each of them said, without being asked, that they were doing this to help others in the community.

The stories themselves, 26 in all, turned out to be less about diabetes than about life in the North. Hockey and hunting, residential school recovery, trying to raise six kids when the price of milk is staggeringly high and twelve people live in your tiny house, childbirth in the most inopportune places, and so on.

The Sweet Bloods of Eeyou Istchee: Stories of Diabetes and the James Bay Cree was released in 2017. Both the Second Edition and audiobook, narrated by Cree artist/musician Matthew Iserhoff of Juno-winning CerAmony, available through our distributor Wilfrid Laurier University Press, were released in 2020. All proceeds go to long-term health care in Eeyou Istchee.

A couple of years after the release of Sweet Bloods, CBHSSJB decided to translate it into several languages. TranscUlturAl: A Journal of Translation and Cultural Studies had already published one of the stories in Chinese translation (translated by Leilei Chen in vol. 12.2). But CBHSSJB wanted the stories to be usable in Indigenous classrooms for language and cultural retention.

We embarked then on another project. CBHSSJB commissioned four translators to translate the entire work: Pat Ningewance for Ojibwe, Luci Bobbish-Salt for Northern East Cree, Louise Blacksmith for Southern East Cree, and Valérie Duro for French. We are working with Mohawk designer Nicole Ritzer to print each of the 26 stories in two series of single-story multi-language format. In one series, a story appears in Ojibwe and English columns, side by side. And in another series, a story appears in Northern East Cree, Southern East Cree, French, and English columns, again side by side. One front cover from each of these series is pictured here. We've just released the first five in each series (distributed through WLUP). We hope to release six or seven every year until all stories are in this format.

For me, this translation project has been a profoundly moving, humbling, and intimate experience as the translators connect with the stories in ways that are often deeply personal. Three of these translators have written briefly about their experiences here in this volume of TranscUlturAl.

These days, I'm at work on another project with Cree storytellers and CBHSSJB. We expect to release the first volume of Finding Our Way Home: Indian Residential School Recovery Stories of the James Bay Cree in 2022.

My own words and the translations of Sweet Bloods stories appear here in TranscUlturAl with the permission of Cree Board of Health and Social Services of James Bay. 